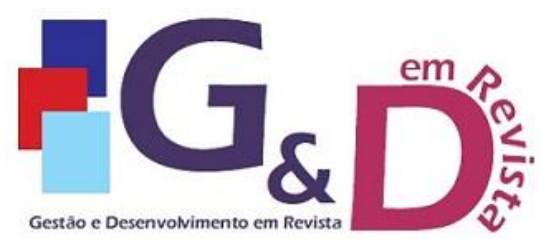

Gestão e Desenvolvimento em Revista

V. 6, N. 2, jul-dez/2020, p. 38-53.

ISSN online: $2446-8738$

Artigo recebido em: 06/11/2020

Artigo aprovado em: 17/02/2021

\title{
CELSO FURTADO E A DIMENSÃO CULTURAL DO SUBDESENVOLVIMENTO
}

\author{
Luiz Carlos Dias \\ Graduação em Ciências Econômicas. Mestrado em Desenvolvimento Regional e Agronegócio. \\ Doutorando em Desenvolvimento Rural Sustentável na Universidade Estadual do Oeste do Paraná - \\ Unioeste, Campus de Marechal Cândido Rondon. Atualmente é professor na Universidade Federal do \\ Paraná - UFPR, Setor Palotina \\ E-mail: Icdias@ufpr.br
}

Clério Plein

Graduação em Economia Doméstica. Mestrado e Doutorado em Desenvolvimento Rural pela Universidade Federal do Rio Grande do Sul. Atualmente é professor do curso de pós-graduação em Desenvolvimento Rural Sustentável da Universidade Estadual do Oeste do Paraná - Unioeste, Campus de Marechal Cândido Rondon.

E-mail: clerioplein@gmail.com

\section{Resumo}

Este trabalho pretende apresentar alguns elementos da base teórica de Celso Furtado que ligam o processo de subdesenvolvimento dos países da América Latina e em especial o Brasil com os conceitos de cultura e, por decorrência, conceitos de dependência e criatividade. Através de uma revisão teórica, procura-se realizar um breve apanhado sobre a formação econômica do Brasil que na geopolítica mundial está inserido sob a condição de dependência e subdesenvolvimento; após, aprofunda-se os conceitos de cultura e subdesenvolvimento em destaque a classificação de Furtado sobre cultura material e não material, em seguida procura-se fazer uma abordagem sobre a condição de subdesenvolvimento tendo em vista o processo de globalização vigente e por fim uma exposição de uma das últimas mensagens de Furtado. Celso Furtado aponta que a saída da condição de subdesenvolvimento passa por decisões políticas que possam aflorar o desenvolvimento endógeno considerando as raízes históricas e culturais do seu povo. De modo geral os apontamentos de Furtado permanecem atuais, percebe-se grande heterogeneidade estrutural no Brasil refletidos em desigualdades na distribuição de renda, educação, saúde e outros, levando a crer que somente uma ruptura na dependência cultural pode nos trazer resultados diferentes.

Palavras-chave: Subdesenvolvimento. Cultura. Dependência.

\begin{abstract}
This academic work intends to put forward some elements of Celso Furtado's theoretical basis that link the underdevelopment process of Latin American countries and especially Brazil with the concepts of culture and, consequently, concepts of dependence and creativity. Through a theoretical revision, it seeks to carry out a brief overview of the economic formation of Brazil, which in world geopolitics is inserted under the condition of dependence and underdevelopment; afterward, the concepts of culture and underdevelopment are deepened, especially Furtado's classification of material and non-material culture, and then an approach to the condition of underdevelopment is sought with a view to globalization process in force and finally an exhibition of one of Furtado's last messages. Celso Furtado points out that the exit from the underdevelopment goes through political decisions that may emerge endogenous development considering the historical and cultural roots of its people. In general, Furtado's notes remain current, one can see great structural heterogeneity in Brazil reflected in inequalities in the income distribution, education, health, and others, leading to believe that only a break in cultural dependency can bring different results.
\end{abstract}

Keywords: Underdevelopment. Culture. Dependency. 


\section{INTRODUÇÃO}

Cultura pode ser entendida como instrução, saber, cultivo, conhecimento (FERREIRA, 2014, p. 215). Aqui procura-se tratar a dimensão cultural de forma que ela possa restringir ou ampliar as possibilidades de um povo, desta forma compete discutir cultura como sinônimo de instrução, saber e conhecimento. Nestes termos, cultura pode ser compreendia como "o complexo dos padrões de comportamento, das crenças, das instituições, das manifestações artísticas, intelectuais etc., transmitidos coletivamente, e típicos de uma sociedade", bem como "o conjunto dos conhecimentos adquiridos em dado campo" (FERREIRA, 2014, p. 215).

Não havendo uma definição clara e objetiva para cultura nas obras de Celso Furtado, procurou-se trabalhar os termos pelos quais o autor percorre esse assunto.

No entanto, durante discurso de posse no Ministério da Cultura em 1986, Furtado aproxima-se de uma definição: "Cultura, para mim, é a dimensão qualitativa de tudo que cria o homem. (...) O homem, com seu gênio criativo, dá significado às coisas, e são essas coisas impregnadas de significação que constituem a nossa cultura". No decorrer de sua exposição o autor conclui: "(...) Portanto, eu diria que a preocupação com o cotidiano, ou a dimensão cotidiana da cultura, contém grande parte da resposta à pergunta que formulei: o que é cultura?" (FURTADO, 2012, p. 51 e 52).

Referindo-se ao processo de subdesenvolvimento, Furtado contrariou formulações teóricas de Rostow (1961), que assegurava que o subdesenvolvimento seria uma etapa do desenvolvimento e que todos os países poderiam alcançar, Celso Furtado foi enfático em descrever que o subdesenvolvimento advém das relações históricas de um país e pode ser persistente ou mesmo impossível de ser ultrapassado a medida que não haja um movimento de descentralização de renda e mobilização dos recursos produtivos a favor do próprio povo, considerando suas características sociais e econômicas (FURTADO, 2004).

A abordagem de Celso Furtado inovou ao refletir como as raízes históricas e culturais dos países estão ligadas à geração, difusão e assimilação da tecnologia, podendo determinar os rumos de uma nação. Para tanto, sua obra discute as relações de poder que os países desenvolvidos exercem sobre os subdesenvolvidos, impondo desde seu padrão de consumo e tecnologia até seus valores culturais. Quando o autor analisa as estruturas dos países subdesenvolvidos considera que a elite econômica e política procura lhes garantir formas de consumo e cultura alheios à realidade local.

$\mathrm{Na}$ atualidade o Brasil está inserido no grupo das economias emergentes, percebe-se um alto nível de consumo de produtos com elevado teor tecnológico, no entanto, isso não se traduz em homogeneização social. A cultura da dependência persiste e arrasta consigo a falta de acesso às escolas, serviços de saúde, moradia digna, inserção ao mercado formal de trabalho, dependência tecnológica, dentre outras deficiências econômicas sociais. É neste sentido que Furtado conduz sua teoria do subdesenvolvimento alicerçado na cultura da dependência.

Neste contexto, sobre a empregabilidade, Barbosa (2019) revela que no ano de 2014 os $50 \%$ mais pobres se apropriavam de 5,7\% de toda a renda do trabalho, no ano de 2019 essa fração cai para 3,5\%, por outro lado, o grupo dos 10\% mais ricos da população recebia $49 \%$ do total da renda do trabalho em 2014 e passou para 52\% em 2019. Sobre a habitação, no ano de 2015 foi estimado uma defasagem 
de 6,355 milhões de domicílios, destes em torno de $84 \%$ concentrava-se na faixa de até três salários-mínimos (FUNDAÇÃO JOÃO PINHEIRO, 2018). O sistema escolar também reproduz diversas desigualdades sociais conforme aponta 0 anuário brasileiro da educação básica 2019. A escolaridade media no Brasil no ano de 2017 entre a faixa de idade de 18 a 27 anos foi de 11,3 anos, na região sudeste esta media ficou em 11,8 anos, enquanto no nordeste estava em 10,6 anos; considerando a população urbana a media estava em 11,6 anos, dois anos a mais que a população rural; a faixa dos $25 \%$ mais ricos da população estudou em média 3,8 anos a mais que os $25 \%$ mais pobres; quanto à raça/cor os anos de estudo dos brancos foi em media de 12,1 anos, enquanto os pardos e pretos foi 10,8 anos. Diante destes dados, evidencia-se a contemporaneidade das obras de Celso Furtado e justifica-se a importância de estudos com esta abordagem.

Para tanto, utiliza-se de metodologia descritiva com abordagem qualitativa, procurando sistematizar algumas contribuições de Celso Furtado e apresentar elementos de sua base teórica metodológica que aproximam as relações de subdesenvolvimento com os conceitos de dependência, cultura e progresso técnico. Partindo de uma teoria do subdesenvolvimento será analisado a construção teórica que o relaciona com a cultura de um povo, mais especificamente os conceitos de centro e periferia, dependência e dualismo estrutural.

Além desta introdução seguem-se mais cinco seções. Na primeira busca-se resgatar a formação econômica do Brasil e o início de sua condição de subdesenvolvimento; na segunda apresenta-se a noção de subdesenvolvimento atrelado ao que o autor denomina de cultura material e não material e o conceito de dependência cultural; na terceira discute-se a ampliação da dominação cultural exercida pelos países desenvolvidos sobre os países periféricos baseado nas relações globais de comercialização; na quarta busca-se descrever as afirmações de Celso Furtado em uma de suas últimas mensagens, por fim, são apresentadas as considerações finais.

\section{DESENVOLVIMENTO}

\subsection{FORMAÇÃO ECONÔMICA E DEPENDÊNCIA CULTURAL}

Conforme destaca Furtado (2005), para analisar o subdesenvolvimento brasileiro é necessário analisar seu contexto histórico e cultural, que devem ser vistos desde sua origem, nas especificidades de sua formação, o qual foi proveniente de um processo de expansão geográfica da Europa do século XVI e a busca de ampliação mercantil de Portugal.

Assim, a cultura brasileira foi formada pela temática portuguesa, no entanto, incorpora características próprias baseadas nas miscigenações dos povos que aqui chegaram.

Com relação a nossa formação cultural, Furtado aponta que:

Nós, brasileiros, podemos afirmar que nossa identidade cultural nasceu inicialmente no plano cultural. Pois se é verdade que, entre nós, o Estado antecedeu à nação, mais razão existe para afirmar que a Cultura antecipou- 


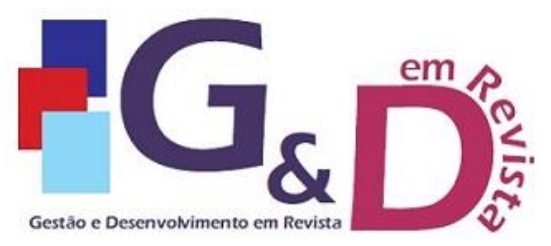

Gestão e Desenvolvimento em Revista V. 6, N. 2, jul-dez/2020, p. 38-53.

ISSN online: $2446-8738$

Artigo recebido em: 06/11/2020

Artigo aprovado em: 17/02/2021

se à existência do Estado. Já no século XVII apresenta-se entre nós o embrião de uma personalidade cultural. Pensemos na força que apresenta nossa criatividade cultural no século XVIII, quando éramos uma simples constelação de feitorias. (FURTADO, 2012, p. 53). destaca:

Referente ao inicio do processo brasileiro de subdesenvolvimento Furtado

\begin{abstract}
Nossa história colonial está marcada por dois ciclos de grande prosperidade: o do açúcar e o do ouro. Ora, no último quartel do século XVIII tem início uma prolongada fase de dificuldades econômicas e transtornos políticos. É a época em que se inicia na Inglaterra a Revolução Industrial, que repercutirá profundamente no sistema de divisão internacional do trabalho. No período de estagnação econômica, que se estende até meados do século seguinte, define-se a situação de subdesenvolvimento que prevalece em nosso país até hoje (...) (FURTADO, 2012, p. 145 e146).
\end{abstract}

Desta forma, o Brasil permaneceu alheio às transformações tecnológicas que se observava na Europa advinda da revolução industrial. Segundo Furtado (1984, p. 27), "a industrialização tardia brasileira foi conduzida no quadro de um desenvolvimento imitativo ou mimético". Assim as atividades produtivas encontramse subordinadas à dependência tecnológica e financeira, bem como, a acumulação de renda foi direcionada ao consumo da elite e da classe média local.

Conforme destaca Rodríguez (2009), na realidade dos países desenvolvidos, observam-se ganhos significativos de produtividade e aumento de excedente causando intensificação da acumulação, diversificação e acréscimo nos padrões de consumo interno, por outro lado, na realidade local, visualizou-se que a renda gerada pela exportação de matéria prima permaneceu concentrada nas mãos dos comercializadores que direcionava o excedente para consumo de produtos importados, tomando os padrões europeus de consumo como referência, processo conhecido como modernização dependente.

Com base nas relações de consumo e inversão produtiva de uma nação, Furtado (2004, p. 2) distingue crescimento econômico de desenvolvimento:

(...) o crescimento econômico, tal qual o conhecemos, vem se fundando na preservação dos privilégios das elites que satisfazem seu afã de modernização; já o desenvolvimento se caracteriza pelo seu projeto social subjacente. Dispor de recursos para investir está longe de ser condição suficiente para preparar um melhor futuro para a massa da população. Mas quando o projeto social prioriza a efetiva melhoria das condições de vida dessa população, o crescimento se metamorfoseia em desenvolvimento (FURTADO, 2004, p. 3 e 4).

Neste contexto de aumento das exportações de produtos primários e crescimento do consumo de importados evidencia-se o distanciamento entre a elite colonial e as demais classes trabalhadoras, os valores culturais europeus viviam as transformações observadas na indústria e passaram a ser enaltecidos e tidos como superiores na colônia, enquanto o povo local era associado ao atraso e sua cultura desprezada. Furtado (1984, p. 22) destaca, "o povo era reduzido a uma referencia 


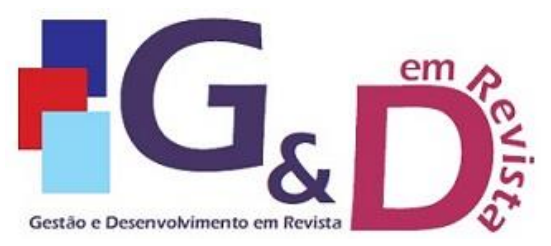

Gestão e Desenvolvimento em Revista

V. 6, N. 2, jul-dez/2020, p. 38-53.

ISSN online: $2446-8738$

Artigo recebido em: 06/11/2020

Artigo aprovado em: 17/02/2021

negativa, símbolo do atraso, atribuindo-se significado nulo à sua herança cultural não europeia e recusando-se valia a sua criatividade".

$\mathrm{Na}$ arena econômica nacional percebe-se uma desconexão entre a acumulação de capital e diversificação da base produtiva alicerçada na inovação e conteúdo tecnológico. Ocorre uma inversão da acumulação para novos padrões de consumo, bem como, o excedente social passa a atender essa dinâmica, determinando um aumento da lacuna da heterogeneidade social, assim, a sociedade permanece alheia dos benefícios do progresso técnico e material, restrito apenas ao núcleo da elite. Nesta relação, Furtado assinala que:

(...) No Brasil o debate sobre as opções do desenvolvimento demanda uma reflexão prévia sobre a nossa cultura, que ponha em relação a lógica dos fins, que a rege, e a dos meios, razão instrumental inerente à acumulação. Como preservar o gênio criativo de nossa cultura diante da assimilação de técnicas que, se aumentam nossa eficácia, não deixam de ser vetores de valores que mutilam nossa identidade cultural? Uma visão de conjunto do processo cultural brasileiro deste fim de século revela, no primeiro plano, o papel crescente da indústria cultural transnacional como instrumento da modernização dependente. No segundo plano, distingue-se uma certa autonomia de criação numa classe média assediada pelos valores dessa indústria, mas que conserva uma face voltada para a massa popular. No terceiro plano, e abarcando todo horizonte, se perfila enfim essa massa popular cada vez mais ameaçada de perder seu caráter cultural específico. A emergência de uma consciência crítica em certos segmentos da classe média está favorecendo a percepção de valores especificamente populares, e permite criar zonas de resistência ao processo de deformação cultural. Uma nova síntese cultural brasileira não seria capaz de se cristalizar sem o fortalecimento dessa consciência crítica. (FURTADO, 2012, p. 186).

Com base nas afirmações de Furtado, Borja (2013) destaca que a partir desse modelo de consumo baseado na importação sem oferecer condição do aparelho produtivo interno de atender essa demanda decorre a dependência tecnológica, ou seja, a partir da deficiência produtiva ocorre uma imposição para adoção dos métodos produtivos dos países centrais ampliando a dependência. Assim, a questão tecnológica aliada ao consumo e a busca pela reprodução do modo de vida dos países centrais configura a dependência cultural brasileira.

\subsection{O ESTABELECIMENTO DA CULTURA DA DEPENDÊNCIA}

As teorias do desenvolvimento passaram a ser discutidas com maior importância após a Segunda Guerra Mundial, o contexto era de afirmação de uma governança global para o novo cenário geopolítico que surgia. Neste período é criada a Organização das Nações Unidas (ONU) que visava a consolidação de uma governança global e a formulação de acordos internacionais no âmbito do GATT (Acordo Geral de Tarifas e Comércio) que, mais tarde, foi substituído pela OMC (Organização Mundial do Comércio), e a fundação do Banco Mundial responsável pela reconstrução dos países que estiveram em conflito. Havia desta forma um envolvimento de todos os países com vistas a estabilidade econômica e crescimento (NIEDERLE e RADOMSKY, 2016). 
$\mathrm{Na}$ América Latina tinha-se a expectativa de superação do subdesenvolvimento, o caminho escolhido foi pela adoção da expansão capitalista através do Estado intervencionista e conservador que utilizando-se do discurso de combate ao socialismo não adotaram reformas estruturais necessárias. As iniciativas associaram o desenvolvimento industrial, tecnológico e financeiro, no entanto, 0 intervencionismo em inúmeros países se tornou nacionalista e ditatorial (NIEDERLE e RADOMSKY, 2016).

Através da inquietude sobre as condições desfavoráveis que vivia a América Latina em relação aos países europeus surge a Comissão Econômica para América Latina - CEPAL, a preocupação central era as questões do desenvolvimento e a relação das distintas trajetórias percorridas pelos países. O entendimento era que cada país está situado dentro de um contexto mundial, no entanto, há particularidades inerentes a cada um, portanto, o receituário desenvolvido para os países europeus poderiam não determinar o mesmo efeito para os países latinos americanos (BORJA, 2009).

Nesta relação, a CEPAL institui o progresso técnico como fator determinante na competitividade entre os países. A partir desta base foi formulado o sistema centro-periferia, que discute a geração, difusão e assimilação do progresso técnico e procura explicar a deterioração dos termos de troca observado entre os países produtores e exportadores de matérias-primas e alimentos em relação aos países industrializados (BORJA, 2009).

A partir desta base analítica que tratava especificamente da relação desigual do comércio entre os países surgiram outras duas linhas teóricas preocupadas em analisar e interpretar as características da industrialização da América Latina: o subdesenvolvimento e a dependência. O subdesenvolvimento demonstra que 0 modo de produção e a tecnologia se difundem apenas em alguns centros do país ao passo que as demais regiões permanecem as formas arcaicas de produção. Já a análise da dependência verifica a necessidade dos países da América Latina em adquirir a tecnologia ou assimilar o progresso técnico dos países centrais, soma-se a essa análise a constatação que o consumo da burguesia local se assemelha ao da burguesia dos países desenvolvidos, ressaltando a aceitação dos comandantes do sistema econômico interno (BORJA, 2009).

Em meio a essas formulações teóricas destaca-se Celso Furtado que procurava formular uma teoria mais ampla que explicasse a condição econômicosocial dos países latinos, para isso abarcou as análises das condições periféricas e de dependência destes países, determinando que esses dois pilares evoluem para uma teoria do subdesenvolvimento.

Assim, segundo Furtado (1984), o subdesenvolvimento tem suas raízes na divisão internacional do trabalho, segundo o autor, com base no princípio das vantagens comparativas os países periféricos produzem e exportam produtos primários utilizando suas extensões de terras e mão de obra barata e são abastecidos por produtos com tecnologia agregada pelos países centrais.

O aumento da produtividade do trabalhador estabelecido pela maior mecanização permite a geração de um volume maior de excedentes, com isso ocorre a diversificação do consumo. Com a divisão internacional do trabalho essas relações passaram a ser distintas.

Assim, Furtado (1984, p. 22 e 23), explica que:

Um país que se especializasse na produção agrícola para a exportação podia ter acesso à moderna tecnologia sob a forma de produtos de 


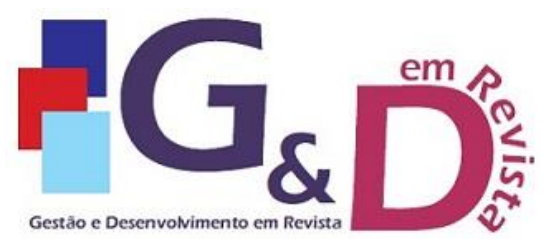

Gestão e Desenvolvimento em Revista

V. 6, N. 2, jul-dez/2020, p. 38-53.

ISSN online: $2446-8738$

Artigo recebido em: 06/11/2020

Artigo aprovado em: 17/02/2021

consumo, sem ter que investir para elevar a produtividade física do trabalho. As vantagens comparativas estáticas criadas pela especialização davam origem a um excedente que permitia pagar os bens de consumo sofisticados que estavam penetrando no mercado internacional. Era o processo de modernização dependente, que outra coisa não é senão a utilização do excedente, gerado pela especialização e retido localmente, para modelar os padrões de comportamento de forma a estimular a importação de manufaturas destinadas ao consumo (FURTADO, 1984, p. 22 e 23).

Desta forma, a condição periférica utiliza-se da assimilação de produtos finais para difusão do progresso técnico com base no aumento das exportações possibilitado pelo aumento da utilização de novas terras ou na intensificação da produção por meio de máquinas e equipamentos importados.

Para viabilizar com maestria a modernização das sociedades periféricas tem-se a integração comercial, observa-se a diversificação da estrutura da demanda sem uma contrapartida na estrutura produtiva, determinando a condição de dependência tecnológica (BORJA, 2009).

Assim, percebe-se que as relações produtivas estão envolta a relações políticas e sociais de uma determinada localidade, a identificação das formas de produção e a apropriação do excedente estabelece um vínculo com os valores culturais e ideológicos formando uma superestrutura. Conforme compreende Furtado, a junção entre criatividade, inovação e técnica forma o sistema de cultura, o qual torna-se um dos componentes de formação do sistema nacional, assim, ela precisa ser contextualizada nas análises que tratam o subdesenvolvimento.

Neste sentido, a técnica pode ser compreendida como autonomia ou subordinação ao exterior, a criatividade entendida como liberdade ou reprodução cultural e as classes sociais com distintos interesses. Desta forma, há uma relação da cultura nacional com o sistema mundial, no entanto, no interior do próprio sistema de cultura há relações específicas, determinadas de cultura material e cultura não material. A cultura material é composta por fatores de produção e progresso técnico, nesta relação, as inovações propiciam a geração de excedentes que ampliam as opções aos membros da sociedade. A cultura não material abarca as relações sociais de produção, a organização política e social, os costumes, a religião etc., é neste campo que uma sociedade explora suas potencialidades criativas e alcança sua auto identificação (RODRÍGUEZ, 2009).

Assim, segundo Furtado (1964), uma característica própria dos dois modelos é a constatação de que a cultura é formada por um conjunto de elementos interdependentes, a partir do momento que determinadas condições possibilitam avançar a tecnologia, automaticamente ocorrerá um novo ajuste que originará uma série de novos processos, repercutindo também na base não material.

A esse respeito Furtado (2012, p. 110) destaca:

(...) A cultura tem que ser observada a um só tempo como um processo cumulativo e como um sistema. É algo que goza de coerência e que não se explica em sua totalidade pelo significado isolado de suas partes em razão dos efeitos de sinergia. (FURTADO, 2012, p. 110).

A partir deste entendimento de Furtado, Borja (2009), analisa que o avanço técnico pode ser entendido como um dos meios mais importantes de mudança 
cultural de um povo. A partir da intensificação tecnológica direcionada a um determinado setor desenrolará uma série de movimentos, pois, a partir de novos bens de consumo e de produção pode-se gerar novas estruturas produtivas, novas relações sociais e novas formas de apropriação do excedente.

A simples absorção de tecnologias não condizentes à realidade das economias subdesenvolvidas determina heterogeneidade estrutural no país, determinando disparidade entre as regiões e dependência externa, características do dualismo estrutural intrínseca ao subdesenvolvimento (FURTADO, 1974).

Conforme destaca Sampaio Jr. (2013), a realidade presente nos países subdesenvolvidos é de modesta acumulação produtiva, bem como, dificuldade de difusão do progresso técnico. Assim, têm-se realidades inteiramente distintas, setores altamente produtivos com base especializada e outro cuja produção atende basicamente a subsistência. Furtado (1961, p. 180), destaca que "...esse tipo de estrutura socioeconômica dualista está na origem do fenômeno do subdesenvolvimento contemporâneo".

A partir destas relações, inicia-se um processo não somente de dualismo produtivo, mas também o dualismo cultural com profunda distinção entre o setor capitalista - reconhecidos como altamente produtivos - e o não capitalista moldando tanto a cultura material como a não-material (BORJA, 2009).

Nos países subdesenvolvidos a forma de produção capitalista em relação ao não capitalista ocorre em ondas, a acumulação de renda dos primeiros é reinvestida no processo produtivo através da aquisição de melhores tecnologias, que por consequência determina uma maior acumulação e assim sucessivamente. O padrão de consumo das elites passa a assemelhar-se aos das elites dos países desenvolvidos, o resultado deste dualismo é o distanciamento social entre os integrantes do sistema capitalista e os excluídos.

Neste sentido, o subdesenvolvimento não se trata meramente de uma fase, estágio ou estado, mas de uma grande e persistente deformação estrutural que não se dissipa com o tempo, pelo contrário, se estabelece uma grande capacidade de reprodução. O desenvolvimento percebido nas transformações de escala global de expansão do sistema capitalista requer o subdesenvolvimento (BRANDÃO, 2012).

\subsection{A PERSISTÊNCIA DA CULTURA DA DEPENDÊNCIA}

A condição de subordinação econômica e social sempre acompanhou os países subdesenvolvidos ao longo da história. Num primeiro momento, a intensificação de produção primária baseada na demanda da Europa acompanhada de entraves à produção manufatureira, num segundo momento verificou-se a política de substituição de importações e mais recente a abertura comercial e mobilidade de capital estrangeiro, desta forma, sob a pretensão de alcançar o desenvolvimento a dinâmica nestes países tem sido de aceitação e adaptação ao que é instituído pelos países centrais (BORJA, 2009).

$\mathrm{Na}$ atualidade o fenômeno da globalização vem impondo um novo ritmo nas estruturas produtivas dos países. Destaca-se as cadeias globais de valor que instituem às empresas transnacionais a utilização do fator de produção que mais Ihes interessa em cada país, bem como, a integração dos mercados financeiros. Como consequência deste novo padrão verifica-se a transferência do poder de 


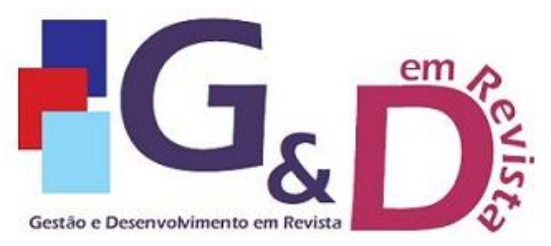

Gestão e Desenvolvimento em Revista V. 6, N. 2, jul-dez/2020, p. 38-53.

ISSN online: $2446-8738$

Artigo recebido em: 06/11/2020

Artigo aprovado em: 17/02/2021

decisão dos Estados subdesenvolvidos ao capital estrangeiro e por consequência a subordinação aos países desenvolvidos.

Sobre essa subordinação dos países subdesenvolvidos em relação as empresas transnacionais Furtado (2000a, p. 9) cita que:

\begin{abstract}
Na lógica das empresas transnacionais, as relações externas, comerciais ou financeiras, são vistas, de preferência, como operações internas da empresa, e cerca de metade das transações do comércio internacional já são atualmente operações realizadas no âmbito interno de empresas. As decisões sobre o que importar e o que produzir localmente, onde completar o processo produtivo, a que mercados internos e externos se dirigir são tomadas no âmbito da empresa, que tem sua própria balança de pagamentos externos e se financia onde melhor lhe convém (FURTADO 2000a, p. 9).
\end{abstract}

Neste sentido, a atuação externa na realidade interna determina uma assimilação das formas produtivas, para isso, há a necessidade de correspondência na formação dos trabalhadores, assim, a dominação passa o ocorrer na educação e por consequência na formação das instituições de ensino. Como forma de legitimação, ocorre também interferências nas estruturas políticas e de poder. Valores culturais e ideológicos de fora são adotados e legitimados internamente exercendo forte representação no sistema político local, conforme destaca Furtado (2000b, p. 79).

\begin{abstract}
A iniciativa se mantém com os interesses externos, cuja atuação ganha flexibilidade e eficácia à medida que se apoia em agentes locais. Esse tipo de burguesia surgida da inserção no sistema de divisão internacional do trabalho tende a identificar-se cultural e ideologicamente com o centro, operando a parte do excedente que lhe corresponde como instrumento da aculturação. Nessas circunstâncias, o processo de modernização alcança máxima intensidade. (FURTADO, 2000b, p.79).
\end{abstract}

Sobre essa relação Sen (2000, p. 47), cita que a cultura e os novos estilos de vida dos países ocidentais estão destruindo os modos de vida e costumes tradicionais. O desenvolvimento econômico pode tornar-se nocivo a uma localidade à medida que conduz à eliminação de suas tradições e herança cultural, sob o argumento de que "é melhor ser rico e feliz do que pobre e tradicional" (SEN, 2000, p. 47).

No sentido de preservação dos valores culturais e ideológicos, a mobilização de consciências e rupturas alicerçadas na diversidade, pluralidade e no embate de ideias não significa necessariamente fragmentação social, mas, pelo contrário, podem significar libertação de energias capazes de cooperar para o fortalecimento das relações sociais. Nesta relação, Furtado (2012, p. 104) assinala que:

Como ato de ruptura, a criatividade alimenta-se com frequência da ação de grupos contestadores que, em uma sociedade aberta, devem encontrar espaço para atuar. Demais, como herança cultural e a criatividade se inserem na pluralidade étnica do país, o avanço na conscientização das populações negras e indígenas é visto como ampliação de nosso horizonte cultural (FURTADO, 2012, p. 104). 
Assim, o desenvolvimento endógeno busca a consolidação de uma identidade própria através das potencialidades criativas inerentes ao acervo cultural da sociedade. Desta forma, políticas capazes de aflorar a criatividade na periferia constituem importantes ações de desenvolvimento.

No entendimento das palavras de Furtado, Brandão (2012) cita que as estratégias dos países subdesenvolvidos devem incorporar mecanismos sociais consolidados nas estruturas da atualidade e na historicidade com intuito de corrigir distorções do passado e rígidas estruturas de poder vigentes. O Estado deve assumir o papel de coordenação e dinamização do sistema econômico, direcionar o processo produtivo conforme suas relações históricas mobilizando forças com intuito de promover a acumulação produtiva.

A noção de desenvolvimento atrelada a obra de Furtado não está vinculada a adoção de níveis de consumo e as formas de cultura dos países centrais, compete o reconhecimento da necessidade de uma distribuição de renda mais igualitária, o acesso da população marginalizada aos serviços do estado como educação, saúde, moradia, segurança, lazer, etc. para isso tona-se mister a construção de ações e políticas públicas que quebrem as correntes das estruturas políticas que representam o atraso. A ampliação das possibilidades que favoreçam a criatividade e consequente desenvolvimento técnico local molda um cenário favorável em todos demais aspectos, contrariando a ideia de que o desenvolvimento requer a destruição do tradicional.

Assim, Furtado (1974, p. 75) esclarece que:

(...) a ideia de desenvolvimento apenas tem sido de utilidade para mobilizar os povos da periferia e leva-los a aceitar enormes sacrifícios, para legitimar a destruição de formas culturais 'arcaicas', para 'explicar' e fazer 'compreender a necessidade' de destruir o meio físico, para justificar formas de dependência que reforçam o caráter predatório do sistema produtivo (FURTADO, 1974, p. 75).

Corroborando a análise de Furtado, Brandão (2012), cita a escala nacional como determinante de criação de oportunidades de acesso a bens e serviços, bem como, aprofundamento de horizontes, enriquecendo a cultura material e não material. Uma sociedade criativa e com uma estrutura que permite a interação da produção com inovação aliado a um sistema de aprendizado científico, tecnológico, educacional e cultural capaz de captar, interpretar e conduzir informações para criação de novas competências respeitando suas especificidades são elementos primordiais no sistema social.

A esse respeito, Rodríguez (2009), aponta que o sentimento de pertencimento de uma sociedade é visto como "força cultural" capaz de gerar importante impulso num projeto de desenvolvimento, para tanto, deve-se somar as forças que convirjam e se retroalimentem, no entanto, a dimensão econômica também deve ser considerada pois possui condições de aliar transformação produtiva e equidade, componentes do desenvolvimento. 


\subsection{CELSO FURTADO E OS DESAFIOS DA NOVA GERAÇÃO}

Este tópico irá se concentrar em uma das últimas mensagens de Celso Furtado. O texto foi publicado na Revista de Economia Política em 2004. A intenção é expor o entendimento mais recente do autor sobre o persistente processo de subdesenvolvimento do Brasil, neste artigo ele apresenta uma perspectiva histórica e desafios sobre o que chama de experiência de mau desenvolvimento, bem como, traça alguns possíveis caminhos para um desenvolvimento qualitativo.

De antemão o autor chama a atenção que apesar das questões tratadas se referirem ao Brasil, "na verdade são problemas comuns à grande parte dos países em desenvolvimento" (FURTADO, 2004, p. 3). Também nas primeiras linhas Furtado (2004, p. 3) destaca a necessidade para uma reflexão sobre os "graves problemas que afligem o mundo em desenvolvimento face ao modelo neoliberal imposto pelo processo de globalização", enfatiza a necessidade de ampliação dos debates sobre os processos que determinam o subdesenvolvimento e a importância de levar as informações ao conhecimento da opinião pública que, "com frequência, os centros de poder mantêm fora de toda visibilidade" (FURTADO, 2004, p. 3).

Sobre o processo histórico Furtado (2004) analisa o significativo crescimento do Brasil nos anos 1950 e 1960 e o intenso processo de industrialização deste período. Confronta o massivo investimento público que propiciou expressiva acumulação em alguns setores com a realidade social da população.

\footnotetext{
(...) os salários reais da massa da população não refletiram o crescimento econômico. A taxa de subemprego invisível, isto é, de pessoas ganhando até um salário mínimo na ocupação principal, manteve-se surpreendentemente alta. $\mathrm{E}$, mais grave, a grande maioria da população rural pouco ou nada se beneficiou desse crescimento (FURTADO, 2004)
}

Destaca o crescimento da classe média neste período, no entanto, pondera que este fato não pode ser tomado como referência face a pobreza e miséria de praticamente um terço da população, ou mesmo, pode ser entendida que o modelo seguido evidenciou o fracasso da política de desenvolvimento adotado.

Frente a essa realidade, Furtado chama atenção que mesmo após o período militar e a sociedade brasileira tendo optado pelo regime democrático ainda persistem as dificuldades em articular formas de desenvolvimento que se traduza em melhorias sociais para a grande maioria dos brasileiros.

A resposta de Furtado para essa realidade caminha pela disposição de toda sua obra, ou seja, crescimento econômico não se funde automaticamente em desenvolvimento, o simples direcionamento de recursos não se faz suficiente para a satisfação das necessidades básicas da população. Para ele o modelo de crescimento verificado no Brasil tem se estabelecido na proteção dos privilégios das elites e suas estigmas de modernização.

Reconhecendo o persistente processo desigual do crescimento brasileiro Furtado aponta que somente a partir de projetos que estabeleçam respostas eficientes para melhoria das condições de vida da população o crescimento se transformará em desenvolvimento.

No entanto, conforme destaca Furtado (2004, p. 4) essa transformação não é automática. 
Ora, essa metamorfose não se dá espontaneamente. Ela é fruto da realização de um projeto, expressão de uma vontade política. As estruturas dos países que lideram o processo de desenvolvimento econômico e social não resultaram de uma evolução automática, inercial, mas de opção política orientada para formar uma sociedade apta a assumir um papel dinâmico nesse processo (FURTADO, 2004, p. 4).

Furtado ressalta o descontrole financeiro brasileiro em sucessivos governos como algo que deve ser combatido em primeiro lugar, no entanto, destaca também que as opções destes governos geralmente apontaram para cortes nos investimentos públicos, gerando efeitos danosos principalmente nas regiões dependentes destas aplicações.

\footnotetext{
Forçar um país que ainda não atendeu às necessidades mínimas de grande parte da população a paralisar os setores mais modernos de sua economia, a congelar investimentos em áreas básicas como saúde e educação, para que se cumpram metas de ajustamento da balança de pagamentos impostas por beneficiários de altas taxas de juros é algo que escapa a qualquer racionalidade (FURTADO, 2004, p. 4).
}

Neste sentido, a prioridade é estabelecer políticas voltadas ao desenvolvimento, para tanto Furtado destaca duas frentes para promover uma "mudança qualitativa no desenvolvimento do país: a reforma agrária e uma industrialização que facilite o acesso às tecnologias de vanguarda" (FURTADO, 2004, p. 4).

Para Furtado a reforma agrária pode gerar três efeitos. Abre-se a possibilidade para que um conjunto significativo da população possa ampliar seus níveis de consumo e isso fará com que a economia tenha uma nova dinâmica. Com melhores rendas a tendência é que diminua o deslocamento da população rural para as zonas urbanas, isso determinará uma menor competitividade na oferta de mão de obra não especializada. Através de uma nova estrutura agrária haverá uma maior oferta de alimentos de consumo popular, diminuindo a pressão sobre a renda das famílias mais pobres (FURTADO, 2004).

Como forma de assegurar o desenvolvimento Furtado (2004, p. 4), reafirma a industrialização como o "centro dinâmico capaz de impulsionar o conjunto do sistema", para tanto, cita a necessidade de acumulação e desenvolvimento técnico. Nesta relação, considera que devido a dimensão continental do Brasil uma política única não será capaz de captar as particularidades regionais do país. Nesta passagem verifica-se a importância dada por Furtado sobre as iniciativas regionais, sobretudo, obedecendo suas particularidades econômicas, sociais e culturais como forma de dinamizar suas potencialidades.

Nesta mensagem, Furtado sintetiza muitas de suas teorias formuladas em diversos livros e textos, por mais de uma vez destaca as políticas enviesadas que beneficiam alguns grupos através da bandeira do desenvolvimento. Nas últimas linhas cita a necessidade de esforço de toda uma geração para que não se repitam os erros do passado e priorize a defesa do desenvolvimento do conjunto da população.

Neste sentido, a conjugação destas últimas palavras de Furtado com o que foi discutido até então requer que o desenvolvimento passa pelo incremento da identidade cultural, criatividade e técnica inerentes ao sistema cultural. 
Desenvolvimento é a utilização de um excedente, o qual abre horizontes de opções, vale dizer, um excedente adicional cria desafio à inventividade (FURTADO, 2012, p. 43). Ademais, um povo culturalmente aflorado reconhece seus direitos e busca uma melhor equidade econômica e social.

\section{CONSIDERAÇÕES FINAIS}

A obra de Celso Furtado percorreu a relação persistente do subdesenvolvimento dos países da América Latina, e em especial do Brasil, sua grande preocupação ao formular suas análises era superar o atraso impregnado nos sistemas econômicos, sociais e políticos desses países.

Segundo Furtado (1961), para entender o processo de subdesenvolvimento deve ser analisada as raízes históricas dos países. No Brasil a colonização foi baseada na exportação primária com cultivo agrícola em extensão e exploração de mão de obra escrava, assim formou-se uma elite desconectada com a realidade nacional, consumidora de produtos importados que não priorizou um movimento de produção manufatureira interna.

Essa relação persiste à medida que o excedente formado por essa base exportadora não realoca recursos para o crescimento industrial endógeno. Assim, no mesmo núcleo tem-se setores altamente produtivos - geralmente atrelado a produção primaria para exportação - e por outro lado, setores arcaicos que não logram competitividade externa, formando um dualismo econômico e produtivo.

Lendo os diferentes apontamentos das obras de Celso Furtado vindos desde meados do século passado dá-se a impressão que nunca fora tão atual, ou mesmo, dada as condições atuais de urbanização, avanço tecnológico e deficiência econômica e social percebe-se um agravamento para o que o autor já chamava atenção à época.

Guardadas as devidas proporções, as bases econômicas e sociais do Brasil na atualidade continuam as mesmas das de mais de quinhentos anos atrás. Nossa formação econômica teve início com a produção açucareira cuja base era extensão de terras, mão de obra barata e engenhos importados, passou-se diversos ciclos econômicos (algodão, borracha, café, etc.) com as mesmas dinâmicas e hoje temos no agronegócio da soja basicamente a mesma relação, ou seja, produção em escala para exportação de forma que o excedente seja canalizado para importação de insumos que intensifiquem ainda mais essa produção, criando elites setorizadas.

A partir desta dinâmica persistente destaca-se que o desenvolvimento é construído a partir de decisões políticas sobre direcionamento do excedente produzido. Neste sentido, torna-se premente a análise da questão cultural do subdesenvolvimento atrelada as estruturas de poder para entender porque mesmo com a alternância política/partidária as ações seguem orientadas na perpetuação do quadro de país subdesenvolvido.

A esse respeito, Brandão (2012, p. 4), analisando a obra de Celso Furtado quanto à cultura do subdesenvolvimento destaca que:

Desenvolvimento é tensão. É distorcer a correlação de forças, importunar diuturnamente as estruturas e coalizões tradicionais de dominação e reprodução do poder. É exercer em todas as arenas políticas e esferas de 


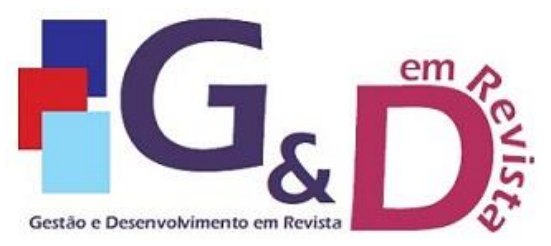

Gestão e Desenvolvimento em Revista V. 6, N. 2, jul-dez/2020, p. 38-53.

ISSN online: $2446-8738$

Artigo recebido em: 06/11/2020

Artigo aprovado em: 17/02/2021

poder uma pressão tão potente quanto o é a pressão das forças que engendram e perenizam o subdesenvolvimento (BRANDÃO, 2012, p. 4).

Com relação a visão de Furtado sobre o processo de desenvolvimento Brandão (2012, p. 2) complementa:

\begin{abstract}
Celso Furtado nos deixa uma mensagem consistente de necessidade contínua de construção de cidadania, dignidade, segurança e proteção, com radicalidade democrática, redistribuição de renda, riqueza, poder e acesso ao Estado, combate às heterogeneidades estruturais e valorização da riqueza cultural civilizacional específica de dados âmbitos e escalas regionais e nacionais (BRANDÃO, 2012, p. 2).
\end{abstract}

Frente a globalização da cultura material e não material no qual relega aos países subdesenvolvidos a condição de simples consumidores, a proposta de mudança passa por iniciativas próprias, alicerçados em políticas que valorize e estimule os valores culturais e fortaleçam a união da sociedade.

Nesse sentido, pensar opções de desenvolvimento que levem em conta a superação do impasse do subdesenvolvimento exige tanto a defesa de um processo endógeno de desenvolvimento quanto uma articulação consistente entre esse processo e o sistema cultural no sentido de reverter a condição de heterogeneidade social e dependência cultural das sociedades periféricas.

Assim, o esforço despendido consiste em transformação social que consolidado em especificidades históricas e culturais sejam capazes de redirecionar a rota de produção e reprodução das desigualdades regionais e nacionais.

\title{
REFERÊNCIAS
}

ANUÁRIO BRASILEIRO DA EDUCAÇÃO BÁSICA. Todos pela educação. São Paulo. Editora Moderna. 2019. Disponível em: $<$ https://www.todospelaeducacao.org.br/_uploads/_posts/302.pdf>. Acesso em 08 ago 2020.

BARBOSA, R. J. Estagnação desigual: desemprego, desalento, informalidade e a distribuição da renda do trabalho no período recente (2012-2019). Brasília: IPEA. 2019.

Disponível

em:

<http://repositorio.ipea.gov.br/bitstream/11058/9949/1/bmt_67_nt_estagnacao_desig ual_desemprego.pdf>. Acesso em: 07 ago 2020.

BORJA, B. Celso Furtado e a cultura da Dependência. Revista Oikos. v. 8 n. 2, p. 247-262, 2009. Disponível em: <http://www.revistaoikos.provisorio.ws/seer/index.php/oikos/article/viewFile/134/120> Acesso em: 30 mar 2020.

BORJA, B. Notas sobre a dimensão cultural na obra de Celso Furtado. In: D'AGUIAR, R. F. (Org.). Celso Furtado e a dimensão cultural do desenvolvimento. Rio de Janeiro: Centro Internacional Celso Furtado de Políticas para o Desenvolvimento, 2013, p. 125-153. 
BRANDÃO, C. Celso Furtado: subdesenvolvimento, dependência, cultura e criatividade. Revista de Economia Política de las Tecnologias de la Información y de la Comunicación. v. XIV, n.1, jan-abr, 2012. Disponível em: <file://C:/Users/Usuario/Downloads/400-Texto\%20do\%20artigo-1058-1-1020120412\%20(1).pdf>. Acesso em: 30 mar 2020.

FERREIRA, A. B. de H. O dicionário da língua portuguesa. Curitiba: Editora Positivo, 2014.

FUNDAÇÃO JOÃO PINHEIRO. Déficit habitacional no Brasil. Diretoria de estatística e informações. Belo Horizonte. 2018. Disponível em: < https://www.mdr.gov.br/images/stories/ArquivosSNH/ArquivosPDF/Publicacoes/capa citacao/publicacoes/deficit-habitacionalBrasil_2015.pdf>. Acesso em: 08 ago 2020.

FURTADO, C. Desenvolvimento e Subdesenvolvimento. Rio de Janeiro: Editora Fundo de Cultura, 1961.

. Dialética do Desenvolvimento. Rio de Janeiro: Editora Fundo de Cultura, 1964.

. O mito do desenvolvimento econômico. São Paulo: Paz e Terra, 1974.

1984.

Cultura e desenvolvimento em época de crise. São Paulo: Paz e Terra,

. O fator político na formação nacional. Estudos avançados, São Paulo, v.14, n.40, p.7-12, Dez. 2000a. Disponível em: $<$ http://www.scielo.br/scielo.php?script=sci_arttext\&pid=S0103-

40142000000300002\&lng=en\&nrm=iso>. Acesso em: 20 Mar. 2020.

. Introdução ao Desenvolvimento: enfoque histórico-estrutural. Rio de Janeiro: Paz e Terra, 2000b.

. Os desafios da nova geração. Revista de Economia Política. v. 24, n. 4, out-dez, 2004, p. 483-486.

Formação Econômica do Brasil. 32ª Ed. São Paulo: Companhia Editora Nacional, 2005.

FURTADO, C.; FURTADO R. F. D'A. (org.) Ensaios sobre cultura e o Ministério da Cultura. Arquivos Celso Furtado. Rio de Janeiro: Editora Contraponto/Centro Internacional Celso Furtado, 2012.

NIERDELE, P. A.; RADOMSKY, G. F. W. Introdução às teorias do desenvolvimento. In: NIERDELE, P. A. e RADOMSKY, G. F. W. (org.). Prefácio. Porto Alegre: Editora da UFRGS, 2016, p. 7-10. 
RODRÍGUEZ, O. Desenvolvimento e cultura. In: RODRíGUEZ, O. O estruturalismo latino-americano. Rio de Janeiro: Civilização Brasileira, 2009, 700p.

ROSTOW, W. W. Etapas do desenvolvimento econômico: um manifesto não comunista. Rio de Janeiro: Zahar, 1961.

SAMPAIO Jr, P. A. A atualidade da teoria do subdesenvolvimento de Celso Furtado. In: D'AGUIAR, R. F. (Org.). Celso Furtado e a dimensão cultural do desenvolvimento. Rio de Janeiro: Centro Internacional Celso Furtado de Políticas para o Desenvolvimento, 2013, p. 69-85.

SEN, A. Desenvolvimento como liberdade. São Paulo: $\mathrm{Ci}$ 